\title{
Oxidation of Polychlorinated Biphenyls by Pseudomonas sp. Strain LB400 and Pseudomonas pseudoalcaligenes KF707
}

\author{
DAVID T. GIBSON,"* DIANA L. CRUDEN, JOHN D. HADDOCK, \\ GERBEN J. ZYLSTRA, $\dagger$ AND JOHN M. BRAND $\ddagger$ \\ Department of Microbiology and Center for Biocatalysis and Bioprocessing, \\ University of Iowa, Iowa City, Iowa 52242
}

Received 28 December 1992/Accepted 21 April 1993

\begin{abstract}
Biphenyl-grown cells and cell extracts prepared from biphenyl-grown cells of Pseudomonas sp. strain LB400 oxidize a much wider range of chlorinated biphenyls than do analogous preparations from Pseudomonas pseudoalcaligenes KF707. These results are attributed to difierences in the substrate specificity of the biphenyl 2,3-dioxygenases from both organisms.
\end{abstract}

Current interest in the microbial degradation of polychlorinated biphenyls (PCBs) stems from the fact that many members of this class of compounds are persistent environmental pollutants (14). Most studies on the degradation of PCBs by aerobic bacteria have been conducted with biphenyl-grown cells. For example, biphenyl-grown cells of Pseudomonas sp. strain LB400 oxidize a wide range of PCBs, including congeners that contain four to six chlorine substituents $(4,5)$. The same PCBs are oxidized by Alcaligenes eutrophus H850 (2-4). The genes (bph) encoding the enzymes responsible for the oxidation of biphenyl to benzoate in LB400 have been cloned (12) and shown to hybridize strongly to the genome of H850 but not to DNA from four other bacterial strains known to degrade PCBs (17). These observations led to the suggestion that DNA probes containing the LB400 bph genes can be used to determine the distribution and fate of LB400 and H850 bph genes in the environment and also to facilitate the quantitation and isolation of new strains containing related genes with potentially greater degradative activity $(12,17)$.

The initial reaction in the degradation of biphenyl by bacteria, including LB400, involves the enzymatic incorporation of both atoms of molecular oxygen into the aromatic nucleus to form cis- $(2 R, 3 S)$-dihydroxy-1-phenylcyclohexa4,6-diene (cis-biphenyl dihydrodiol) $(8,9,18)$. The enzyme that catalyzes this reaction, biphenyl 2,3-dioxygenase, has not been studied in detail (9). However, the nucleotide sequences of the bph genes encoding biphenyl 2,3-dioxygenase in LB400 (6) and a different pseudomonad, Pseudomonas pseudoalcaligenes KF707 (16), have been determined. The sequences from both organisms show significant homology (52 to $66 \%$ identity at the predicted amino acid level) to the structural genes $(\operatorname{tod} C 1 C 2 B A)$ encoding the multicomponent toluene dioxygenase from Pseudomonas putida F1 (20). These data suggest that the biphenyl 2,3dioxygenases in LB400 and KF707 are organized as shown in Fig. 1. Thus, it is not surprising to find that the todC1C $2 B A D E$ genes from $F 1$ hybridize to the isofunctional genes in LB400 (19). However, the relationship does not

\footnotetext{
* Corresponding author.

$\dagger$ Present address: Center for Agricultural Molecular Biology, Cook College, Rutgers, State University of New Jersey, New Brunswick, NJ 08903-0231.

$\ddagger$ Present address: Department of Biochemistry, University of Fort Hare, Alice 5700, South Africa.
}

extend to enzyme activity. The $\mathrm{F} 1$ toluene dioxygenase cannot oxidize chlorinated biphenyls containing more than two chlorine substituents (19), and toluene is not a substrate for the biphenyl 2,3-dioxygenase in LB400 cell extracts. There is considerably greater homology, at the nucleotide and predicted amino acid levels, between the individual components of the biphenyl 2,3-dioxygenases from LB400 and KF707 (Table 1). Nevertheless, the results presented below indicate that there are wide differences between the substrate specificities of the biphenyl 2,3-dioxygenases of the two organisms.

Cultures of Pseudomonas sp. strain LB400 (5) and $P$. pseudoalcaligenes KF707 (7) were provided by Herman L. Finkbeiner, Research and Development Center, General Electric Company, Schenectady, N.Y., and Kensuke Furukawa, Department of Agricultural Chemistry, Kyushu University, Fukuoka, Japan, respectively. Both organisms were grown in a mineral salts medium (15) containing $0.005 \%$ (wt/vol) yeast extract and $0.3 \%$ (wt/vol) biphenyl. Cells were harvested in the logarithmic phase of growth, washed twice with $50 \mathrm{mM}$ sodium phosphate buffer ( $\mathrm{pH} \mathrm{7.5),} \mathrm{and} \mathrm{resus-}$ pended in the same buffer to a turbidity of 1.0 at $600 \mathrm{~nm}$. The transformation procedures with defined PCB congener mixes $1 B$ and $2 B$ were essentially those of Bedard et al. (4). PCB congeners were separated on a $25-\mathrm{m}(0.2-\mathrm{mm}$ inside diameter) nonpolar fused silica capillary column at $210^{\circ} \mathrm{C}$ with inlet and electron capture detector temperatures set at $250^{\circ} \mathrm{C}$. The carrier gas was helium $(0.7 \mathrm{ml} / \mathrm{min})$, and injections were split 100:1. The makeup gas for the electron capture detector was nitrogen $(24 \mathrm{ml} / \mathrm{min})$. The reported depletion percentages were calculated by normalization to the recovery of $2,4,6,2^{\prime}, 4^{\prime}$-pentachlorobiphenyl, a nondegradable internal standard, from experimental and perchloric acid-treated controls.

Table 2 shows the results obtained when biphenyl-grown cells of LB400 and KF707 are incubated for $24 \mathrm{~h}$ with congener mixtures $1 \mathrm{~B}$ and $2 \mathrm{~B}$. The congeners oxidized by LB400 are the same as those reported previously for this organism $(4,5)$, with minor differences in the extent of degradation observed with 4,4'-dichlorobiphenyl and some of the more highly chlorinated molecules. KF707 has been shown to oxidize 4-, 3,4-, 2,4,5-, 2,3-, 2,4'-, and 2,4,4'chlorobiphenyls (7). The first three substrates, 4-, 3,4-, and 2,4,5-chlorobiphenyls, are not components of congener mixes $1 B$ and $2 B$ and were not investigated in this study. However, we were able to confirm the oxidation of 2,3-, 


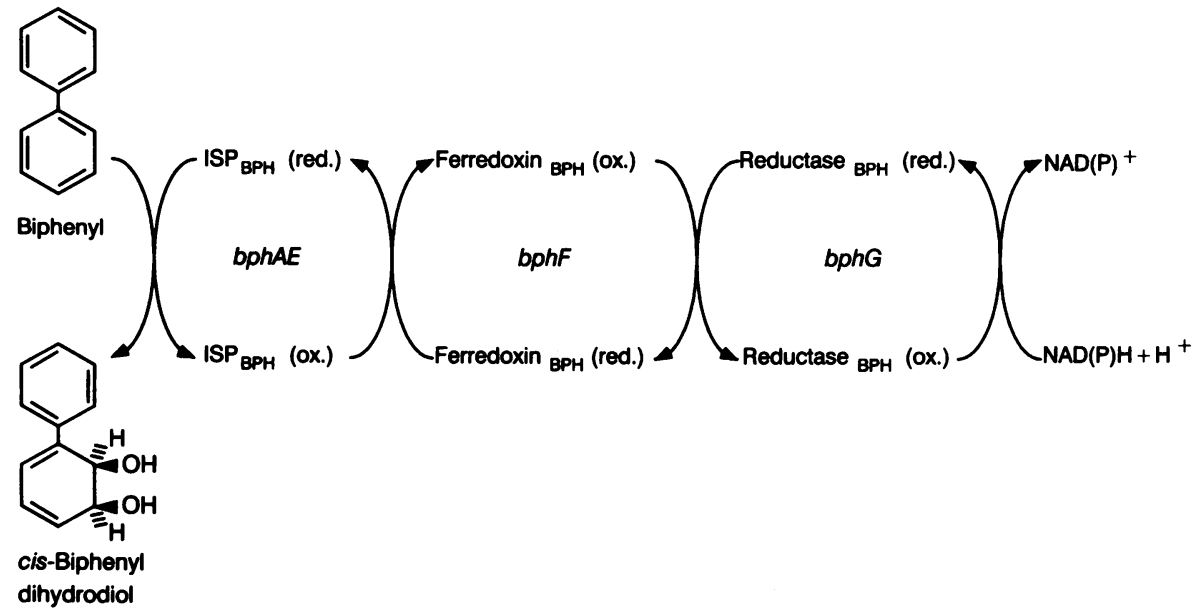

FIG. 1. Proposed organization of the biphenyl 2,3-dioxygenase complex in Pseudomonas sp. strain LB400 and P. pseudoalcaligenes $\mathrm{KF} 707$. The flow of electrons from $\mathrm{NAD}(\mathrm{P}) \mathrm{H}$ through ferredoxin ${ }_{\mathrm{BPH}}$ reductase (Reductase $\mathrm{BPH}_{\mathrm{BPH}}$ ) and a [2Fe-2S] ferredoxin (Ferredoxin ${ }_{\mathrm{BPH}}$ ) to the terminal oxygenase component (ISP ${ }_{\mathrm{BPH}}$ ) is based on homology of the bph genes with the todC1C2BA genes that encode the individual components of toluene dioxygenase $(6,16,20)$. The bph genes in LB400 have been identified as $b p h A$ (ISP ${ }_{\mathrm{BPH}}$, large subunit), bphE (ISP $\mathrm{BPH}_{\mathrm{BPH}}$, small subunit), $b p h F$ (ferredoxin ${ }_{\mathrm{BPH}}$ ), and $b p h G$ (ferredoxin ${ }_{\mathrm{BPH}}$ reductase). The isofunctional $b p h$ genes in KF707 have been designated bphA1A2A3A4 (16). Abbreviations: ox., oxidized; red., reduced.

$2,4^{\prime}$-, and 2,4,4' -chlorobiphenyls by KF707. A comparison of the results presented in Table 2 reveals that $\mathrm{LB} 400$ and KF707 show similar substrate specificities with respect to the oxidation of $2,3-, 2,4^{\prime}-, 2,4,4^{\prime}-, 2,5,4^{\prime}-, 2,3,2^{\prime}, 3^{\prime}-$, and $2,4,3^{\prime}, 4^{\prime}$-chlorobiphenyls. However, LB400 also oxidizes $2,2^{\prime}$ - and 2,5,2'-chlorobiphenyls and congeners containing chlorine substituents at the 2,5 positions on one ring and two or three chlorine substituents at the positions on the second ring shown in Table 2 . With the exception of 2,5,4'-trichlorobiphenyl, KF707 shows little or no oxidation of these substrates. The greater versatility of LB400 with respect to PCB degradation is also seen in the oxidation of $2,4,2^{\prime}, 4^{\prime}-$, $2,4,5,2^{\prime}, 3^{\prime}$-, and $2,4,5,2^{\prime}, 4^{\prime}, 5^{\prime}$-chlorobiphenyls, which are not oxidized by KF707. However, KF707 is superior to LB400 with respect to the degradation of $4,4^{\prime}$-dichlorobiphe- nyl. It has been noted previously for LB400 that the presence of chlorine at the 2 position enhances the degradation of $2,4,4^{\prime}$-trichlorobiphenyl relative to 4,4'-dichlorobiphenyl (4). We recently described the preparation of LB400 cell extracts that oxidize biphenyl at the 2,3 position (9). This procedure, used to prepare cell extracts from biphenylgrown cells of KF707 and LB400, enabled us to examine the possibility that the differences in congener specificity between LB400 and KF707 are due to differences in the efficiency of transport of the various chlorinated biphenyls. Transformations were performed in duplicate as described above with incubation times of 0.5 and $2 \mathrm{~h}$. Reaction mixtures contained cell extract (LB400, $1.1 \mathrm{mg}$ of protein; KF707, $0.94 \mathrm{mg}$ of protein), NADH (1.0 mM), and ferrous ammonium sulfate $(0.4 \mathrm{mM})$ in $1.0 \mathrm{ml}$ of $50 \mathrm{mM} 2-(N-$

TABLE 1. Comparison of the nucleotide and predicted amino acid sequences of the bph genes encoding the individual components of biphenyl 2,3-dioxygenase from Pseudomonas sp. strain LB400 and P. pseudoalcaligenes KF707 ${ }^{a}$

\begin{tabular}{|c|c|c|c|c|c|c|c|c|}
\hline \multirow{3}{*}{ Function } & \multicolumn{6}{|c|}{ Sequence } & \multirow{2}{*}{\multicolumn{2}{|c|}{ Sequence difference }} \\
\hline & \multicolumn{3}{|c|}{ LB400 } & \multicolumn{3}{|c|}{ KF707 } & & \\
\hline & Gene & Region $^{b}$ & $\operatorname{Size}^{b}$ & Gene & Region & Size & Nucleotides & Amino acids \\
\hline Large subunit & $b p h A$ & $1439-2818$ & $1,380(459)^{c}$ & bphA1 & 500-1876 & $1,377(458)$ & $46(3)^{d}$ & $19(1)^{e}$ \\
\hline Small subunit & bphE & $2936-3502$ & 567 (188) & bphA2f & $1994-2560$ & 567 (188) & 2 & 1 \\
\hline Unknown & ORF $1^{g}$ & $3540-3959$ & 420 (139) & ORF3 & $2598-3017$ & 420 (139) & 1 & 1 \\
\hline Ferredoxin & $b p h F$ & $4034-4363$ & 330 (109) & bphA3 & $3092-3421$ & 330 (109) & 2 & 1 \\
\hline Reductase & bph $G$ & $4360-5586$ & $1,227(408)$ & bphA4 & $3418-4644$ & $1,227(408)$ & 2 & 1 \\
\hline
\end{tabular}

${ }^{a}$ Nucleotide and amino acid sequences were compared by an alignment of the respective sequences by the GAP program of the University of Wisconsin Genetics Computer Group. Differences between the sequences were noted by visual inspection. Sequences were obtained from GenBank, using accession numbers M83673 and M86348 for KF707 and LB400, respectively.

$b$ In nucleotides.

$c$ The number of amino acids is given in parentheses.

${ }^{d}$ The nucleotide sequences of the $b p h A$ and $b p h A 1$ genes, encoding the large subunits of the terminal oxygenases from LB400 and KF707, respectively, show 46 bases that are mismatched. In addition, three adjacent bases in $b p h A$ are not present in $b p h A 1$.

e The amino acid sequences of the large subunits show 19 amino acids that are mismatched and that the LB400 large subunit contains one amino acid more than the KF707 large subunit.

$f$ Open reading frame analysis identified nucleotide 1919 as the starting point for the KF707 bphA2 gene (16). However, comparison with the highly homologous todC2 gene, for which the starting point is known (20), indicates that $b p h A 2$ begins at position 1994 . This is also the position reported for the isofunctional bphE gene in LB400 (6). Thus, for the purpose of comparison, we have used position 1994 as the starting nucleotide for the KF707 bphA2 gene.

${ }^{g}$ LB400 and KF707 both have an open reading frame (ORF) with an unknown function between bphE (bphA2) and bphF (bphA3). 
TABLE 2. Oxidation of PCB congeners by biphenyl-grown cells and cell extracts of LB400 and KF707

\begin{tabular}{|c|c|c|c|c|}
\hline \multirow[b]{2}{*}{ Congener } & \multicolumn{4}{|c|}{$\%$ Depletion $^{a}$} \\
\hline & $\begin{array}{l}\text { LB400 } \\
\text { cells }\end{array}$ & $\begin{array}{c}\text { LB400 } \\
\text { extracts }^{b}\end{array}$ & $\begin{array}{l}\text { KF707 } \\
\text { cells }\end{array}$ & $\begin{array}{c}\text { KF707 } \\
\text { extracts }^{b}\end{array}$ \\
\hline $2,3-$ & 100 & 100 & 100 & 100 \\
\hline $2,4^{\prime}-$ & 100 & 100 & 100 & 100 \\
\hline $2,2^{\prime}-$ & 100 & 100 & 18 & 0 \\
\hline $2,5,2^{\prime}-$ & 100 & 100 & 10 & 0 \\
\hline $2,5,4^{\prime}-$ & 98 & 100 & 100 & 54 \\
\hline $2,3,2^{\prime}, 3^{\prime}-$ & 100 & 100 & 81 & 50 \\
\hline $2,3,2^{\prime}, 5^{\prime}$ & 100 & 100 & 9 & 0 \\
\hline $2,5,3^{\prime}, 4^{\prime}-$ & 100 & 100 & 18 & 9 \\
\hline $2,5,2^{\prime}, 5^{\prime}-$ & 100 & 100 & 9 & 0 \\
\hline $2,4,5,2^{\prime}, 5^{\prime}-$ & 100 & 98 & 0 & 0 \\
\hline $2,3,4,2^{\prime}, 5^{\prime}-$ & 97 & 96 & 0 & 0 \\
\hline 2,4,5,2',3'- & 50 & 53 & 0 & 0 \\
\hline $4,4^{\prime}-$ & 25 & 11 & 100 & 71 \\
\hline $2,4,4^{\prime}-$ & 89 & 54 & 99 & 94 \\
\hline $2,4,2^{\prime}, 4^{\prime}-$ & 81 & 86 & 0 & 0 \\
\hline $2,4,3^{\prime}, 4^{\prime}-$ & 43 & 34 & 31 & 24 \\
\hline 3,4,3',4'- & 6 & 11 & 0 & 0 \\
\hline $2,4,5,2^{\prime}, 4^{\prime}, 5^{\prime}-$ & 41 & 61 & 0 & 0 \\
\hline $2,4,6,2^{\prime}, 4^{\prime}-(\text { IS })^{c}$ & 0 & 0 & 0 & $\overrightarrow{0}$ \\
\hline
\end{tabular}

a Combined data obtained from the incubation of intact cells and cell extracts with congener mixtures $1 \mathrm{~B}$ and $2 \mathrm{~B}$. Congener depletion differences between LB400 and KF707 (for both intact cells and cell extracts) are boxed. Values for LB400 extracts were the same at 0.5 and $2 \mathrm{~h}$. Values for KF707 extracts were determined at 0.5 and $2 \mathrm{~h}$. The 2 -h values are shown.

${ }^{b}$ The specific activities of biphenyl 2,3-dioxygenase in cell extracts of LB400 and KF707 were 2.5 and $1.4 \mathrm{nmol}$ of cis-biphenyl dihydrodiol formed per min per mg of protein, respectively (9).

$c$ (IS), internal standard.

morpholino)ethanesulfonic acid (MES) buffer ( $\mathrm{pH}$ 6.0). The KF707 mixtures also contained $1.0 \mu \mathrm{M}$ flavin adenine dinucleotide. The congener specificities of LB400 and KF707 cell extracts are significantly different and parallel the results obtained with intact cells (Table 2). Thus, differences in congener transport are not responsible for the differences in PCB oxidation observed with LB400 and KF707.

The defined congener depletion assay used in this study provides valuable comparative information on the substrate specificity of the enzyme(s) responsible for the initial reaction in the degradation of a wide range of PCB congeners. Care must be taken when one compares the extents of degradation of different congeners, since Bedard et al. (4) have shown that the results can be influenced by other congeners present in the reaction mixture. Nevertheless, the patterns of congener depletion observed with LB400 cells and extracts are similar to each other and clearly different from the results of analogous experiments conducted with KF707.

The wide range of PCB congeners oxidized by LB400 may be due to the presence of more than one enzyme capable of initiating PCB degradation or to the ability of biphenyl 2,3-dioxygenase to catalyze hydroxylation at other positions on the biphenyl molecule $(1,13)$. Although the existence in LB400 of more than one enzyme capable of initiating the oxidation of PCBs cannot be ruled out at this time, it seems unlikely for the following reasons. First, the only biphenyl dioxygenase that we have been able to detect in LB400 cell extracts is the multicomponent 2,3-dioxygenase system predicted from sequence data $(6,9)$. Second, homogeneous preparations of the oxygenase component of the LB400 biphenyl 2,3-dioxygenase system oxidize 2,5,2',5'-tetrachlo- robiphenyl at the 3,4 position (8a). Third, all attempts to demonstrate, by mutagenesis and subcloning, the presence of more than one oxygenase in LB400 have been unsuccessful (12).

The differences in congener specificity between LB400 and KF707 probably reflect differences in the active sites of the oxygenase components of the biphenyl 2,3-dioxygenase present in both organisms. It has been suggested that the small subunit of the oxygenase component of toluate 1,2 dioxygenase may play a role in substrate recognition (10). This seems unlikely for biphenyl 2,3-dioxygenase, as the small subunits of the oxygenase components of LB400 and KF707 differ by only a single amino acid $(6,16)$. There are 20 amino acid differences between the predicted sequences for the large subunits of the terminal dioxygenases from LB400 and KF707, but most of them can be regarded as conservative. Histidine and tyrosine residues are probable ligands for binding iron at the active site in other multicomponent systems similar to biphenyl 2,3-dioxygenase (11). Thus, the change of histidine and phenylalanine at positions 255 and 277 in the KF707 large subunit to glutamine and tyrosine in the LB400 large subunit may play a role in determining the substrate specificity of each enzyme. We are currently purifying the biphenyl 2,3-dioxygenases from LB400 and KF707 to determine the factors responsible for substrate specificity.

Finally, the results suggest that DNA-DNA hybridization experiments may produce unreliable results when they are used to determine the presence and biodegradation potential of bacteria in environments contaminated with PCBs.

This work was supported in part by contract CR-816352 from the U.S. Environmental Protection Agency's Biosystems Technology Development Program and U.S. Public Health Service grant GM29909 from the National Institute of General Medical Sciences.

We thank P. R. Sferra, EPA project officer, for interest, support, and suggestions and Peter Lau for helpful discussions.

\section{ADDENDUM IN PROOF}

Similar results to those presented here for intact cells of LB400 and KF707 were reported in a poster by F. J. Morello and B. D. Erickson at a conference, The Role of Reducing Toxicity and Exposure to Environmental Pollutants, held at the National Institute of Environmental Health Sciences, 26 and 27 April 1993.

\section{REFERENCES}

1. Bedard, D. L. 1989. PCB dechlorination by aerobic bacteria, p. 15-23. In H. L. Finkbeiner and S. B. Hamilton (ed.), General Electric Company research and development program for the destruction of PCBs, eighth progress report. General Electric Corporate Research and Development, Schenectady, N.Y.

2. Bedard, D. L., M. J. Brennan, and R. Unterman. 1984. Bacterial degradation of PCBs: evidence of distinct pathways in Corynebacterium sp. MB1 and Alcaligenes eutrophus H850, p. 4-1014-118. In G. Addis and R. Komai (ed.), Proceedings of the 1983 PCB seminar. Electrical Power Research Institute, Palo Alto, Calif.

3. Bedard, D. L., M. L. Haberl, R. J. May, and M. J. Brennan. 1987. Evidence for novel mechanisms of polychlorinated biphenyl metabolism in Alcaligenes eutrophus H850. Appl. Environ. Microbiol. 53:1103-1112.

4. Bedard, D. L., R. Unterman, L. H. Bopp, M. J. Brennan, M. L. Haberl, and C. Johnson. 1986. Rapid assay for screening and characterizing microorganisms for the ability to degrade polychlorinated biphenyls. Appl. Environ. Microbiol. 51:761-768.

5. Bopp, L. H. 1986. Degradation of highly chlorinated PCBs by Pseudomonas strain LB400. J. Ind. Microbiol. 1:23-29. 
6. Erickson, B. D., and F. J. Mondello. 1992. Nucleotide sequencing and transcriptional mapping of the genes encoding biphenyl dioxygenase, a multicomponent polychlorinated biphenyl-degrading enzyme in Pseudomonas strain LB400. J. Bacteriol. 174:2903-2912.

7. Furukawa, K., and T. Miyazaki. 1986. Cloning of a gene cluster encoding biphenyl and chlorobiphenyl degradation in Pseudomonas pseudoalcaligenes. J. Bacteriol. 166:392-398.

8. Gibson, D. T., R. L. Roberts, M. C. Wells, and V. M. Kobal. 1973. Oxidation of biphenyl by a Beijerinckia species. Biochem. Biophys. Res. Commun. 50:211-219.

8a.Haddock, J. D., and D. T. Gibson. Unpublished data.

9. Haddock, J. D., L. M. Nadim, and D. T. Gibson. 1993. Oxidation of biphenyl by a multicomponent enzyme system from Pseudomonas sp. LB400. J. Bacteriol. 175:395-400.

10. Harayama, S., M. Rekik, and K. N. Timmis. 1986. Genetic analysis of a relaxed substrate specificity aromatic ring dioxygenase, toluate 1,2-dioxygenase, encoded by TOL plasmid pWWO from Pseudomonas putida. Mol. Gen. Genet. 202:226234.

11. Mason, J. R., and R. Cammack. 1992. The electron transport proteins of hydroxylating bacterial dioxygenases. Annu. Rev. Microbiol. 46:277-305.

12. Mondello, F. J. 1989. Cloning and expression in Escherichia coli of Pseudomonas strain LB400 genes encoding polychlorinated biphenyl degradation. J. Bacteriol. 171:1725-1732.

13. Nadim, L. M., M. J. Schocken, F. K. Higson, D. T. Gibson, D. L. Bedard, L. H. Bopp, and F. J. Mondello. 1987. Bacterial oxidation of polychlorinated biphenyls, p. 395-402. In Proceedings of the 13th Annual Research Symposium on Land Disposal, Remedial Action, Incineration, and Treatment of Hazardous
Waste. EPA/600/9-87/015. U.S. Environmental Protection Agency, Cincinnati, Ohio.

14. Safe, S. H. 1984. Microbial degradation of polychlorinated biphenyls, p. 361-370. In D. T. Gibson (ed.), Microbial degradation of organic compounds. Marcel Dekker, Inc., New York.

15. Stanier, R. Y., N. J. Palleroni, and M. Doudoroff. 1966. The aerobic pseudomonads: a taxonomic study. J. Gen. Microbiol. 43:159-271.

16. Taira, K., J. Hirose, S. Hayashida, and K. Furukawa. 1992. Analysis of $b p h$ operon from the polychlorinated biphenyldegrading strain of Pseudomonas pseudoalcaligenes KF707. J. Biol. Chem. 267:4844-4853.

17. Yates, J. R., and F. J. Mondello. 1989. Sequence similarities in the genes encoding polychlorinated biphenyl degradation by Pseudomonas strain LB400 and Alcaligenes eutrophus H850. J. Bacteriol. 171:1733-1735.

18. Ziffer, H., K. Kabuto, D. T. Gibson, V. M. Kobal, and D. M. Jerina. 1977. The absolute stereochemistry of several cis-dihydrodiols microbially produced from substituted benzenes. Tetrahedron 33:2491-2496.

19. Zylstra, G. J., S. Chauhan, and D. T. Gibson. 1990. Degradation of chlorinated biphenyls by Escherichia coli containing cloned genes of the Pseudomonas putida F1 toluene catabolic pathway, p. 290-302. In Proceedings of the 16th Annual Hazardous Waste Research Symposium: Remedial Action, Treatment, and Disposal of Hazardous Waste. EPA/600/9-90/037. U.S. Environmental Protection Agency, Cincinnati, Ohio.

20. Zylstra, G. J., and D. T. Gibson. 1989. Toluene degradation by Pseudomonas putida F1: nucleotide sequence of the todC1C2 $B A D E$ genes and their expression in Escherichia coli. J. Biol. Chem. 264:14940-14946. 